\title{
Stress im Kindesalter beschleunigt das Altern
}

\begin{abstract}
Die Telomerlänge ist ein Indikator für die Lebenserwartung einer Zelle und gilt als ein wichtiger Faktor beim Altern. Frühere Studien hatten bereits gezeigt, dass bestimmte äußere Einflüsse die Verkürzung der Telomere beschleunigen können - wie etwa Rauchen, Übergewicht und chronischer Stress. Traumata in der Kindheit galten bereits seit längerem als möglicher Einflussfaktor. Ein definitiver Nachweis hat aber noch ausgestanden.
\end{abstract}

— Um diesen zu erbringen, entschieden sich Wissenschaftler der Duke University in Durham, N.C. (USA), eine Untergruppe der sogenannten E-Risk-Studie auszuwerten. Bei dieser Langzeituntersuchung wurden mehr als tausend Zwillingspaare, die in den Jahren 1994 und 1995 geboren wurden, zusammen mit ihren Familien bis heute begleitet. Von 236 Kindern waren im Alter von fünf und zehn Jahren Abstriche aus der Mundschleimhaut für DNA-Analysen genommen worden. Die Erziehungsberechtigten dieser Kinder wurden zu möglichen Gewalterlebnissen, denen die Kinder ausgesetzt waren, befragt.

Die Auswertung ergab, dass knapp $42 \%$ der Kinder in ihrem Leben bereits Opfer von Misshandlungen, Mobbing oder häuslicher Gewalt gewesen waren. Bei diesen Kindern hatten sich die Telomere in den fünf Jahren zwischen den beiden DNA-Tests deutlich stärker verkürzt als bei ihren Altersgenossen, die keine Gewalt erlebt hatten.

Der Zusammenhang blieb auch bestehen, wenn die Forscher den sozioökonomischen Status, den Body-MassIndex und das Geschlecht mit in die Auswertung einbezogen,

Exposure to violence during childhood is associated with telomere erosion from 5 to 10 years of age: a longitudinal study. Published online on 24 April 2012 in 2012 Molecular Psychiatry; doi: $10.1038 / \mathrm{mp} 2012.32$
- I. Shalev et al.

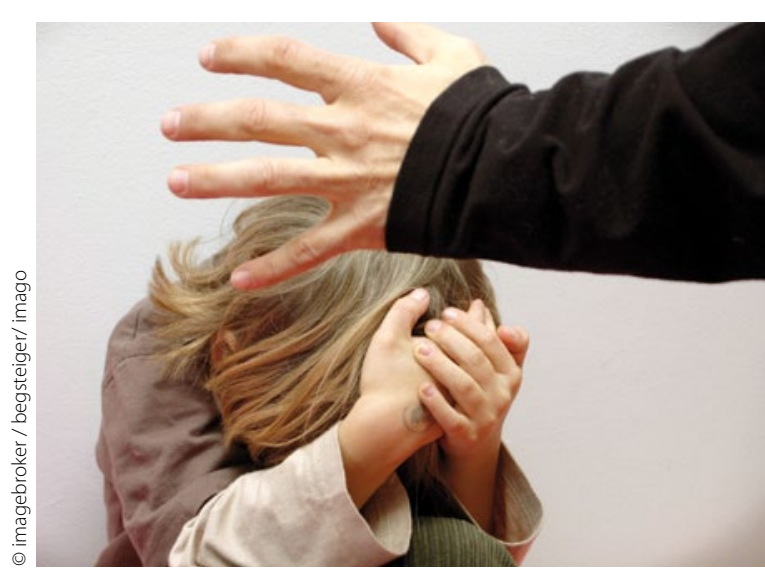

Verkürzen Gewalterlebnisse die Telomere in den Zellen?

\section{Kommentar}

Es wird vermutet dass der Stress das Immunsystem übermäßig aktiviert oder die Menge an sogenannten freien Radikalen im Körper erhöht und dass dies wiederum die Telomere beeinflusst. Die Ergebnisse sollen in größeren Studien und mit älteren Kindern überprüft werden.

K. MALBERG =

\section{Achtung:}

\section{Hier muss der Dummy durch eine Anzeige ersetzt werden !!}

